NASA/TM-1999-209172

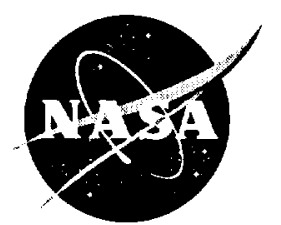

Parametric Studies of the Ejector Process Within a Turbine-Based Combined-Cycle Propulsion System

Nicholas J. Georgiadis, James F. Walker, and Charles J. Trefny Glenn Research Center, Cleveland, Ohio

Prepared for the

36th Aerospace Sciences Meeting \& Exhibit

sponsored by the American Institute of Aeronautics and Astronautics

Reno, Nevada, January 12-15, 1998

National Aeronautics and

Space Administration

Glenn Research Center

May 1999 
The NASA Lewis Research Center has undergone a name change to the NASA John H. Glenn Research Center at Lewis Field. Both names appear in this document.

Available from

NASA Center for Aerospace Information

7121 Standard Drive

Hanover, MD 21076

Price Code: A03
National Technical Information Service 5285 Port Royal Road Springfield, VA 22100 Price Code: $\mathrm{A} 03$ 
AIAA $98-0936$

\title{
Parametric Studies of the Ejector Process Within a Turbine-Based Combined-Cycle Propulsion System
}

\author{
Nicholas J. Georgiadis", James F. Walker, and Charles J. Trefny" \\ National Aeronautics and Space Administration \\ Lewis Research Center \\ Cleveland, Ohio 44135
}

\begin{abstract}
The ejector process within a turbine-based combined-cycle (TBCC) propulsion system is investigated using the NPARC Navier-Stokes code. The TBCC concept integrates a turbine engine with a ramjet into a single propulsion system that may efficiently operate from takeoff to high Mach number cruise. At the operating point considered, corresponding to a flight Mach number of 2.0 , an ejector serves to mix flow from the ramjet duct with flow from the turbine engine. The combined flow then passes through a diffuser where it is mixed with hydrogen fuel and burned.

Three sets of fully turbulent Navier-Stokes calculations are compared with predictions from a cycle code developed specifically for the TBCC propulsion system. A baseline ejector system is investigated first. The Navier-Stokes calculations indicate that the flow leaving the ejector is not completely mixed, which may adversely affect the overall system performance. Two additional sets of calculations are presented; one set that investigated a longer ejector region (to enhance mixing) and a second set which also utilized the longer ejector but replaced the no-slip surfaces of the ejector with slip (inviscid) walls in order to resolve discrepancies with the cycle code. The three sets of Navier-Stokes calculations and the TBCC cycle code predictions are compared to determine the validity of each of the modeling approaches.
\end{abstract}

\section{Introduction}

Air-breathing propulsion systems are receiving heightened interest for enabling low-cost access to space and atmospheric hypersonic cruise missions. Although greater emphasis has been placed on the challenges of achieving higher flight speeds where supersonic combustion ramjet or scramjet operation is required, additional efforts are addressing the equivalently important low speed propulsion mode that is necessary

\footnotetext{
- Senior Member AIAA.
}

to accelerate the vehicle from the ground to speeds where ram compression can provide sufficient thrust. One such effort is a NASA Lewis Research Center program to develop an integrated turbine-based combined-cycle (TBCC) propulsion system. The NASA Lewis TBCC concept is attractive because it combines a highly reliable and efficient low speed system, the turbine engine, with a "dual-mode" scramjet for high speed operation in a manner that eliminates component redundancy. As a result, system complexity and weight are minimized. In addition, the concept is based on a current non-afterburning turbine engine and thus is considered near-term and low-risk technology. A comprehensive description of the concept, including its operating modes, is provided in Ref. 1 .

Briefly, the concept uses a common inlet, hydrogen burner, and nozzle for both engine systems as shown in Fig. 1. The use of a common burner and nozzle is made possible by the ejector action that aerodynamically isolates the high-pressure turbine exhaust stream from the ram/scram jet flow stream. The ejector process also mixes the two streams so that a homogeneous flow enters the nozzle and hydrogen burner. A review of ejector technology, with emphasis on thrust augmentation, is provided in Ref. 2. While complete mixing is desirable for ejector performance and combustion efficiency, it may not be practical from the standpoint of the flight vehicle. The ejector may need to be extremely long to achieve complete mixing which would adversely impact vehicle size and weight Consequently, analyses were initiated to characterize the operation and performance of the TBCC ejector if not fully mixed.

A variety of numerical tools are available for investigating important operational parameters of propulsion systems employing ejectors. These tools vary in complexity from one-dimensional cycle and ejector codes to full Navier-Stokes codes. Cycle codes offer the capability to quickly and easily analyze several variations in flow conditions and ejector geometry. Navier-Stokes codes, although much more computationally expensive, can provide more details of flow development and can capture features such as twodimensional effects, flow separations, and mixing layer development, which cycle codes are not able to provide. In this study, the NPARC Navier-Stokes code was employed to obtain two-dimensional turbulent calculations of the TBCC ejector system. 
In this report, the discussion is organized as follows. The baseline configuration is presented, which includes both the geometry and the flow conditions at the operational point investigated. A description of the Navier-Stokes methods (including initial calculations which investigated turbulence model and grid density sensitivities) and TBCC cycle code is provided next. A set of Navier-Stokes calculations for the baseline TBCC system, in which the back pressure of the ejector process was varied, is presented and compared with the cycle code predictions. Two additional sets of calculations are presented; one set that investigated a significantly longer ejector region (in order to enhance mixing) and a second set which also utilized the longer ejector but replaced the no-slip surfaces of the ejector with slip walls (to model complete mixing without undue wall shear losses). The three sets of NavierStokes calculations and the TBCC cycle code predictions are compared to determine both the validity of the modeling approaches and the operational characteristics of the TBCC ejector concept.

\section{Baseline Ejector Geometry}

The TBCC engine concept was designed to enable high Mach number operation during which a scramjet would be the operating propulsion system. As a result, the TBCC engine was integrated around a generic dual-mode scramjet flow path. The portion of the TBCC engine of interest in this study is shown in Fig. 2. Station numbering corresponds to the convention provided in Ref. 1. The ramjet flow path is of constant area up to the entrance to the mixing section (station 4). The turbine engine nozzle uses a twodimensional convergent nozzle with a throat at station 5 (the entrance to the ejector mixing section) and has a $20^{\circ}$ inflow angle. The ramjet and turbine engine streams enter the mixing section, which is of constant area up to station 6 . Flow leaving the mixing section enters a $20^{\circ}$ diffuser, and is burned with hydrogen fuel at station 7. The region modeled with the Navier-Stokes calculations extended up to, but did not include, the location of the hydrogen fuel spray bars.

\section{Flow Conditions}

The analysis conducted here investigated a point where the ratio of ramjet to turbine engine mass flow is approximately 0.5 . The point is at a flight Mach number of 2.0 at an altitude of 31,450 feet. The turbine engine provides flow at a total pressure of 50 psia and a total temperature of $1815 \mathrm{R}$ while the ramjet duct provides flow at a total pressure of 29.5 psia and a total temperature of $732 \mathrm{R}$. For the Navier-Stokes calculations, these total conditions were specified at the turbine engine and ramjet stream inflows shown in Fig. 2. Static pressure was specified at the end of the diffuser as the outflow boundary.
Numerical Modeling

The Navier-Stokes solver used for this study was the two-dimensional version of the NPARC code. NPARC is a general purpose Navier-Stokes solver that is jointly supported by NASA Lewis Research Center and U.S. Air Force Arnold Engineering Development Center. The capabilities of the code and several references describing applications to which the code has been applied are provided in Ref. 3. For the turbulent calculations obtained in this study, two turbulence models were initially employed, the Chien low Reynolds number $k-\varepsilon$ (two turbulent transport equations) model (Ref. 4) and the Spalart-Allmaras (one turbulent transport equation) model (Ref. 5). The Chien $k-\varepsilon$ model was used because it generally provides more accurate calculations of mixing dominated flows than other one or iwo equation turbulence models. The Spalart-Allmaras model was also investigated because it has been shown to provide more accurate calculations of diffuser flows with strong adverse pressure gradients than other turbulence models including $k-\varepsilon$ models (Refs. 6 and 7). Note in Fig. 2 that following the constant area mixing section, there is a $20^{\prime \prime}$ diffusing section. Because the two most dominant flow features for this ejector nozzle were expected to be mixing of two streams and then flow (mixed or not) passing through the large angle diffuser where flow separation may occur, initial calculations were obtained with both turbulence models to determine which model provided more realistic results.

The first computational grid had 161 points in the axial flow direction, and 105 points in the direction perpendicular (vertical) to the flow direction. A second grid with 261 axial points and 105 vertical points was also constructed to determine any sensitivity of the flow solutions to axial grid spacing. Both grids were packed to no-slip walls (including the upper and lower boundaries for the turbine engine, ramjet, ejector, and diffuser regions) such that the first point off the wall was at an average $y+$ of approximately 1.5, with this average $y+$ based on mixed flow conditions. The grid packing to walls was based on guidelines obtained from grid studies discussed in Ref. 8, and as a result. was not varied here.

For the initial calculations in which turbulence model and grid spacing sensitivities were examined, the back pressure (just upstream of the hydrogen spray bars in the diffuser) was set to a value corresponding to .508 times the total pressure of the ramjet stream $\left(\mathrm{P}_{7} / \mathrm{P}_{1.1 \mathrm{~m}}\right.$ $=0.508$ ). Comparing initial solutions obtained with the Chien $k-\varepsilon$ and Spalart-Allmaras models, it was found that both models indicated very similar shear layer growth in the mixing section. The Spalart-Allmaras solution required approximately 4 hours to converge on an SGI Power Indigo 2 workstation while the Chien $k-\varepsilon$ required approximately 6 hours to converge. The Spalart-Allmaras model was used for all subsequent calculations because it provided nearly the same mixing 
layer growth predictions as the $k-\varepsilon$ model at a lower computational cost, and would be expected to provide more accurate calculations of the flow in the diffuser as the back pressure was raised (as shown in Ref. 7). Solutions obtained with the grids having 161 and 261 points in the axial direction were nearly identical, and as a result, subsequent calculations for the baseline ejector configuration used the smaller grid with 161 axial points.

The cycle code used in this study was developed to design and analyze the complete TBCC propulsion system (Ref. 9). The code employs onedimensional aerodynamic and thermodynamic analysis methods to model the TBCC propulsion components across the flight envelope from sea level static to Mach 6.0 at altitude. Of particular interest to this study is the ejector analysis, which is based on theory developed by Addy, Dutton, and Mikkelsen (Ref. 10).

The ejector analysis utilizes a main control volume extending from stations 4 and 5 to station 6 . and assumes that the turbine engine and ramjet streams are completely mixed at station 6 . Inputs to the control volume include primary (turbine engine exhaust) Mach number and flow angle; the area ratios between the primary, secondary, and exit; and the total pressure and temperature ratios between the primary and secondary. Ramjet flow rate is limited by choking at either the entrance to the ejector region, at an aerodynamic (Fabri) throat, or at station 6 (Refs. 11 and 12). For the ejector geometry and operating conditions considered in this study, the cycle code predicted the presence of a Fabri choke. A second series of control volume relations defined from station 4 and 5 to the Fabri choke location are solved to determine the corresponding flow rate. The maximum ejector back pressure at which the ramjet flow rate is limited by choking is referred to as the ejector's "critical point," and it is considered the operating point producing maximum propulsion system specific net thrust and specific impulse. The ejector operates "sub-critically" when the back pressure is increased beyond the critical point, which reduces the ramjet flow rate. Ejector back pressure is controlled by the location and mixture ratio of the hydrogen burner.

\section{Results}

The initial NPARC calculations, which were primarily intended to investigate turbulence model and grid sensitivity effects, also indicated that the flow leaving the mixing section separated from the top wall just after the $20^{\prime \prime}$ turn into the diffuser. Consequently, a change was made to the ejector configuration by replacing the $20^{\circ}$ straight diffuser ramp with an initial ramp of $10^{\prime \prime}$ followed by the $20^{\prime \prime}$ diffuser. This is reflected in the grid shown in Fig. 3, which will be referred to as the baseline grid (and configuration) in the rest of this report. A set of calculations was then obtained for this baseline configuration to determine the effects of increasing back pressure on the operation of the ejector. Of particular interest was the mass now rate of the ramjel stream and flow development in the mixing region. While the actual boundary condition for the NPARC calculations was specified at the end of the diffuser (station 7), it will be more convenient to refer to the mass averaged static pressure at the end of the mixing section (station 6) in the following comparisons. The case with $P_{7} / P_{t-r a m}=0.508$ corresponds to $P_{h} / P_{1 \cdot \text { ram }}=0.438$.

Mach number contours for this case are provided in Fig. 4. Figure 4a shows contours for the entire ejector system, while Fig. $4 b$ shows the flow details near the beginning of the mixing section. Note that while the turbine engine stream is supersonic from the beginning of the mixing section, the ramjet flow accelerates from subsonic to supersonic conditions through an aerodynamic throat (the location of the Fabri choke). Beyond the Fabri choke, the shear layer between the turbine engine and ramjet streams grows slightly by the end of the constant area mixing section, but there are clearly two distinct streams entering the diffuser. In the diffuser, a series of oblique shock waves compress the flow to raise the static pressure to that specified at the outflow boundary.

Additional cases were examined in which the back pressure was raised to determine effects on ramjet flow and the flow structure in the ejector. As the back pressure is raised, the ramjet flow rate remains constant at $\beta_{\max }=0.476$ ( $\beta$ is the ratio of the ramjet mass flow rate to the turbine engine mass flow rate) until the ejector's critical point is reached. Figure 5 shows Mach number contours for a series of specified back pressures around the critical point. The case with $\mathrm{P}_{6} / \mathrm{P}_{1 \cdot \mathrm{fam}}=$ 0.775 (Fig. 5b) corresponds to this critical point for the baseline contiguration. In Figs. $5 a$ and $5 b$, the Fabri structure is present (as detailed in Fig. 4b), but in Figs. $5 \mathrm{c}$ and $5 \mathrm{~d}$, this structure is gone. A drop in ramjet flow accompanies the loss of the Fabri choke.

For the same ramjet and turbine engine total conditions, the TBCC cycle code predicted a critical point corresponding to $P_{6} / P_{1 . r u m}=0.740$ and $\beta_{n+3 x}=$ 0.529 . One of the assumptions of the TBCC cycle code was that the ramjet and turbine engine streams were completely mixed by the end of the mixing section (station 6). The Navier-Stokes calculations, on the other hand, indicated that the ramjet and turbine engine streams do not completely mix and essentially remain two isolated flows entering the diffuser. Consequently. the lower energy ramjet stream is the first to be affected by increasing back pressure. In order to determine if the extent of mixing affected the overall performance of the ejector and to resolve discrepancics with the cycle code, additional Navier-Stokes calculations were obtained for a modified ejector configuration with a significantly longer mixing section.

In Refs. 13 and 14, a correlation for mixing layer growth is given, which was constructed from 
examination of several experimental data bases for planar shear layers:

$$
\frac{d}{d x}=0.165 \frac{(1-r)\left(1+s^{1 / 2}\right)}{2\left(1+r s^{1 / 2}\right)}
$$

where $\mathrm{db} / \mathrm{dx}$ is the shear layer growth rate, $\mathrm{r}$ is the ratio of velocities of the two streams, and $s$ is the ratio of the densities. Using this correlation and flow conditions of the ramjet and turbine engine streams, a constant area mixing section that is five times as long as that of the baseline configuration would be required to completely mix the two streams. Although such a long mixing section would be impractical for a realistic flight vehicle, a computational grid for a new ejector configuration with this mixing section was constructed to determine the effect of mixing on the pressure at the ejector critical point and to investigate the onedimensional assumptions of the cycle code.

As with the baseline configuration, grid sensitivity studies were conducted for this longer mixing section configuration. Three grids having 161 , 261 , and 361 points in the axial direction were compared. The number of vertical points was 105 for all three grids. Initial calculations for the longer configuration indicated that the grids with 261 and 361 axial points produced the same solution, but that several flow features were lost using the grid with only 161 axial points. Grids were packed to walls per the same guidelines used for the baseline configuration grid. As a result, the grid with 261 axial points and 105 vertical points (shown in Fig. 6) was used for subsequent calculations in which the back pressure was varied as before with the baseline configuration.

Figure 7 shows Mach number contours for the initial case examined with $P_{7} / P_{1 \cdot \text { ram }}=0.508$. Near the end of the mixing section, the turbine engine and ramjet streams are much more thoroughly mixed than in the baseline configuration. However, the flow structure near the beginning of the mixing section as shown in Fig. $7 \mathrm{~b}$ (near the Fabri choking location) is very similar to that in the baseline configuration (compare with Fig. $4 b$ ). In addition, the maximum ramjet flow rate is identical to that for the baseline configuration, $\beta_{\max }=$ 0.476 , and the ejector critical point (Fig. 8) is between $\mathrm{P}_{6} / \mathrm{P}_{1-\mathrm{ram}}=0.761$ and $\mathrm{P}_{6} / \mathrm{P}_{1-\mathrm{ram}}=0.789$. Although these pressures are very similar to those for the baseline configuration, viscous losses for this longer mixing section were likely responsible for lowering the static pressure at the ejector critical point. Calculations obtained with the longer mixing section indicated a smaller region of separated flow in the diffuser along the lower wall at higher back pressures (compare Mach number contours in diffuser for Figs. 5 and 8 ) and a smaller rate of decrease in ramjet flow with increasing back pressure (beyond the ejector critical point).

Analysis of this ejector configuration with a longer mixing section did not resolve discrepancies in maximum entrained ramjet flow between the NavierStokes calculations and the TBCC cycle code predictions. A third set of calculations was obtained where viscous effects along the bottom and top walls of the ejector were removed by replacing the no-slip boundaries with slip (inviscid) walls. The long ejector geometry was used, and the walls providing the upper boundary of the ramjet stream and lower boundary of the turbine engine stream were maintained as no-slip walls, in order for the turbulent boundary layers along these two surfaces to merge into the turbulent mixing layer. The grid used for these calculations was very similar to that for the long ejector calculations with viscous walls (261 axial points and 105 vertical points). The grid packing near the top and bottom walls of the ejector was relieved to accommodate the slip-wall boundary conditions used in the NPARC calculations.

Figure 9 shows Mach number contours for the same flow conditions examined for the other two sets of Navier-Stokes calculations, $P_{1} / P_{1 \text { rram }}=0.508$. Although no boundary layers grow along the top and boltom walls of the ejector, the flow structure is quite similar to the previous cases with viscous walls, especially near the Fabri choking location (Fig, 9a). In addition, the maximum ramjet flow is the same as before, $\beta_{\max }=0.476$. As the back pressure is raised, however, the ejector critical point is not reached until a significantly higher back pressure than that for the viscous wall cases. Figure 10 shows that the ejector critical condition occurs between $P_{6} / P_{1 \text { r.rm }}=0.887$ and $P_{6} / P_{1 \cdot \text {.rsm }}=0.903$. In the viscous wall calculations, increasing the back pressure resulted in thickening and then separation of the boundary layer in the diffuser. which eventually resulted in the loss of the Fabri choke. For these calculations with slip walls along the ejector walls, the effects of the higher back pressure feed upstream not through a ramjet side boundary layer, but instead through a normal shock.

Figure 11 summarizes the variation of entrained ramjet flow with pressure at the end of the constant area mixing section for the three sets of Navier-Stokes calculations and for the TBCC cycle code. At lower back pressures, all three of the NavierStokes approaches produce the same maximum ramjet flow rate, which is lower than that predicted by the TBCC cycle code. As mentioned previously, the ejector critical point is reached at nearly the same $\mathrm{P}_{h} / \mathrm{P}_{1 . \mathrm{r}_{\mathrm{j}} \mathrm{m}}$ for the Navier-Stokes calculations obtained with viscous ejector walls, although viscous losses (along the top and bottom walls of the ejector) likely reduced the maximum achievable pressure for the longer mixing section. However, as the back pressure is raised above the ejector critical point, the ejector with shorter mixing section experiences a sharper drop in ramjec how than does the longer ejector. The ejector modeled with a long mixing section and inviscid walls along the top and bottom walls of the ejector maintained maximum ramjet flow for higher back pressures (higher $P_{h} / P_{1 \cdot \text { rtam }}$ ) 
than the other Navier-Stokes approaches, but still did not resolve differences between the Navier-Stokes calculations and TBCC cycle code predictions of maximum ramjet flow.

As a last attempt to determine the reason for these differences, the ejector configuration with a long mixing section and inviscid ejector walls was modified to reduce the turbine engine stream inflow angle from $20^{\circ}$ to $10^{\circ}$ and $0^{\circ}$. For the TBCC ejector concept, a $20^{\circ}$ inflow angle of the turbine stream may be necessary for integrating the overall system within a reasonable volume. The Navier-Stokes calculations obtained here indicated that a two-dimensional flow structure near the Fabri choke resulted from the turbine stream entering at an angle. The flow structure included a pressure and velocity gradient across the height of the ejector duct. While the one-dimensional TBCC cycle code does account for inflow angle, it obviously can not capture the pressure and velocity gradient predicted by the Navier Stokes analysis. Figure 12 shows that for a turbine engine inflow of $0^{\circ}$, the Navier-Stokes and TBCC approaches indicate nearly identical maximum ramjet flow, which is expected since the turbine and ramjet flows enter the mixing section axially, with no two-dimensional effects. It is also noted that the mass flow entrained through the ramjet stream is significantly higher than at $20^{\circ}$. As the turbine engine inflow angle is increased to $10^{\circ}$ and $20^{\circ}$, two-dimensional effects increase, as does the difference in ramjet flows predicted by the Navier-Stokes and cycle code approaches.

\section{Conclusions}

The Navier-Stokes calculations of the TBCC ejector obtained in this study indicate that the baseline ejector is not sufficiently long to mix the ramjet and turbine engine streams. An ejector with mixing section five times as long as the baseline would be required to completely mix the flows, which would be impractical for an actual flight vehicle. Results described in this report indicated that the back pressure corresponding to the ejector critical point and maximum ramjet flow are not strongly influenced by the extent of mixing, but that the drop in the ramjet flow with increasing pressure beyond the ejector critical point is less severe with the longer mixing section. Further analysis of the ejector system would be required to quantify the impact of incomplete mixing on the overall propulsion system performance. If it were to be determined that incomplete mixing results in significantly degraded performance, some mixing enhancement device (i.e. lobed chutes or tabs) may be necessary to increase the mixing rate within a reasonable ejector length.

In comparing results produced by the NPARC Navier-Stokes code and TBCC cycle code, effects of mixing layer development and viscous losses in the mixing section could only be captured by the NavierStokes calculations. In addition, the two-dimensional flow structure at the Fabri choke indicated by the
Navier-Stokes analysis could not be captured by the cycle cade and resulted in approximately a 10 percent difference in maximum ramjet flow predicted by the two approaches. The two-dimensional flow structure near the Fabri choke location was the result of the turbine engine stream entering the mixing section at $20^{\circ}$. Forcing the two streams to enter the mixing section axially resulted in essentially identical ramjet flows predicted by the Navier-Stokes and cycle code approaches. While a turbine engine inflow angle of nearly $20^{\circ}$ may be necessary for practical integration of the TBCC propulsion system components, reducing this angle increases the maximum flow allowed through the ramjet flow path.

\section{References \\ 1. Trefny, C.J., and Benson, T.J., "An Integration of the Turbojet and Single-Throat Ramjet," NASA TM 107085, December 1995.}

2. Bevilaqua, P.M., "Advances in Ejector Thrust Augmentation," SAE Paper 872322, 1988.

3. Cooper, K., "NPARC 2.0 - Features and Capabilities," AIAA Paper 95-2609, July 1995.

4. Chien, K-Y, "Predictions of Channel and Boundary Layer Flows with a Low Reynolds Number Turbulence Model," AIAA Journal, Vol. 20, No. 1, Jan. 1982. pp.33-38.

5. Spalart, P.R., and Allmaras, S.R., "A One-Equation Turbulence Model for Aerodynamic Flows," AIAA Paper 92-0439, Jan. 1992.

6. De Henau, V., Raithby, G.D.. and Thompson, B.E.. "Prediction of Flows With Strong Curvature and Pressure Gradient Using the k- $\varepsilon$ Model," ASME Journal of Fluids Engineering, Vol. 112, March 1990, pp. 4047.

7. Bardina, J.E., Huang, P.G., and Coakley, T.J., "Turbulence Modeling Validation, Testing, and Development," NASA TM-110446, April 1997. 8. Georgiadis, N.J., Dudek, J.C., and Tierney, T.P., "Grid Resolution and Turbulent Inflow Boundary Condition Recommendations for NPARC Calculations," AIAA Paper 95-2613, July 1995. 9. Benson, T.J., Trefny. C.J., and Walker, J.F., "Interactive Design Tool for Turbine Based Combined Cycle Engines," AIAA Paper 97-3160, July 1997. 10. Addy, A.L., Dutton, J.C., Mikkelsen, C.D., "Supersonic Ejector-Diffuser Theory and Experiments," Report No.UILU-ENG-82-4001. Dept. of Mechanical and Industrial Engineering. University of Illinois at Urbana-Champaign, Urbana, IL, August 1981. 11. Dutton, J.C., and Carroll, B.F., "Limitation of Ejector Performance Due to Exit Choking," $A S M E$ Journal of Fluids Engineering, Vol. 110, March 1988. pp. 91-93.

12. Fabri, J. and Siestrunck, R., "Supersonic Air Ejectors," Advances in Applied Mechanics. Vol. V., Academic Press, New York, 1958, pp. 1-34. 
13. Goebel, S.G., "An Experimental Investigation of Compressible Turbulent Mixing Layers," Ph. D.

Thesis, Univ. of Illinois at Urbana-Champaign, 1990.
14. Goebel, S.G., and Dutton, J.C., "Velocity Measurements of Compressible Turbulent Mixing Layers," AIAA Paper 90-0709, 1990.

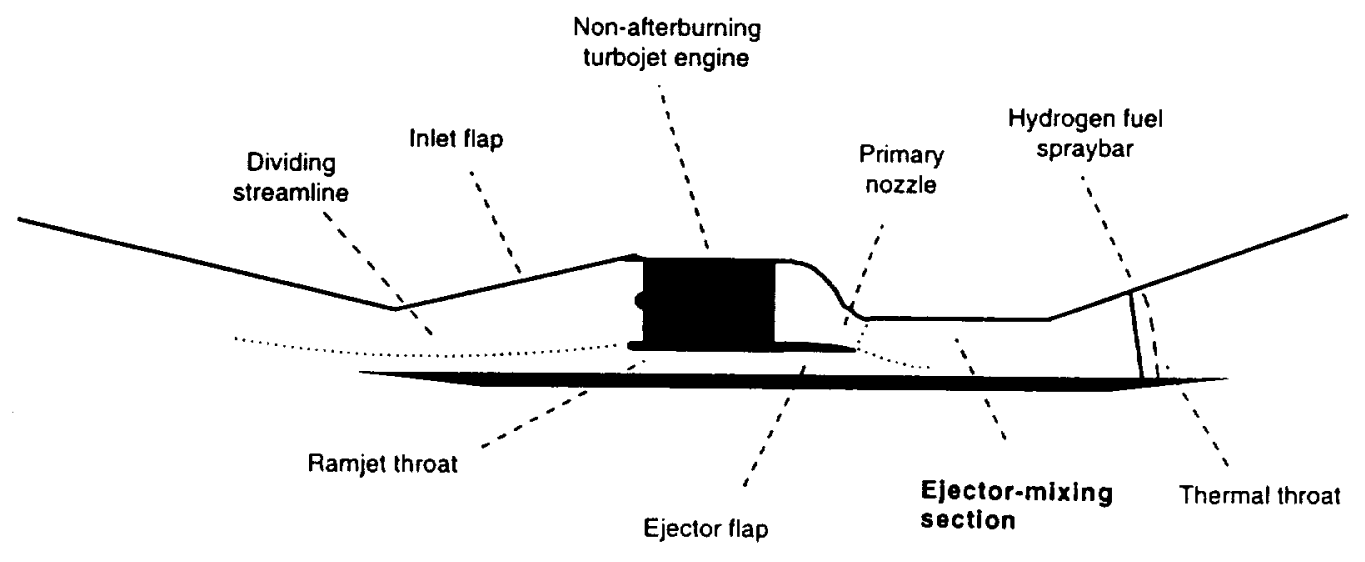

Fig. 1 TBCC propulsion system flowpath

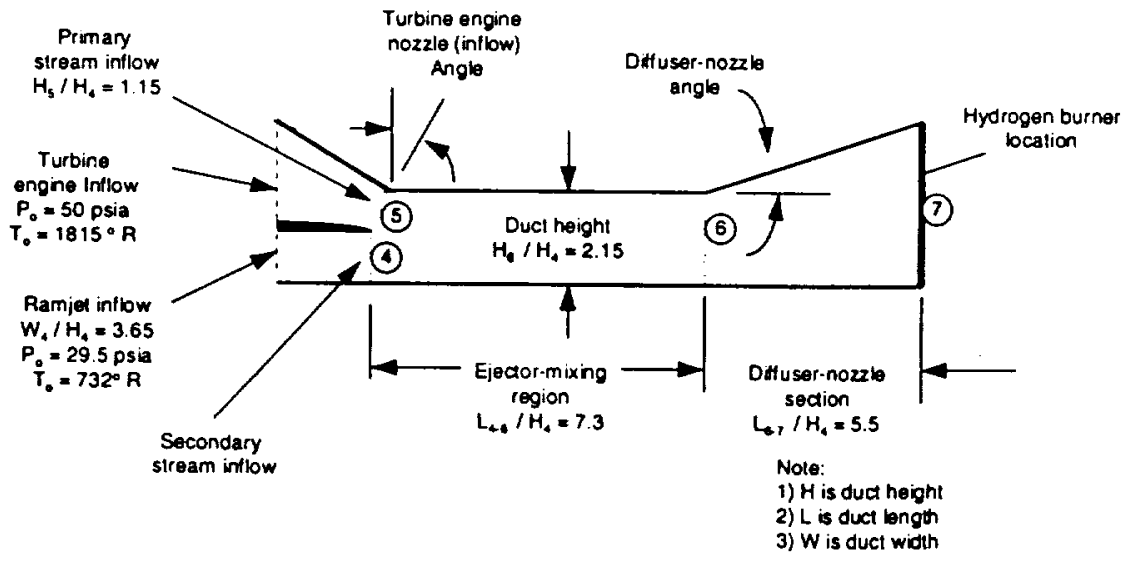

Fig. 2 Schematic of baseline TBCC ejector 


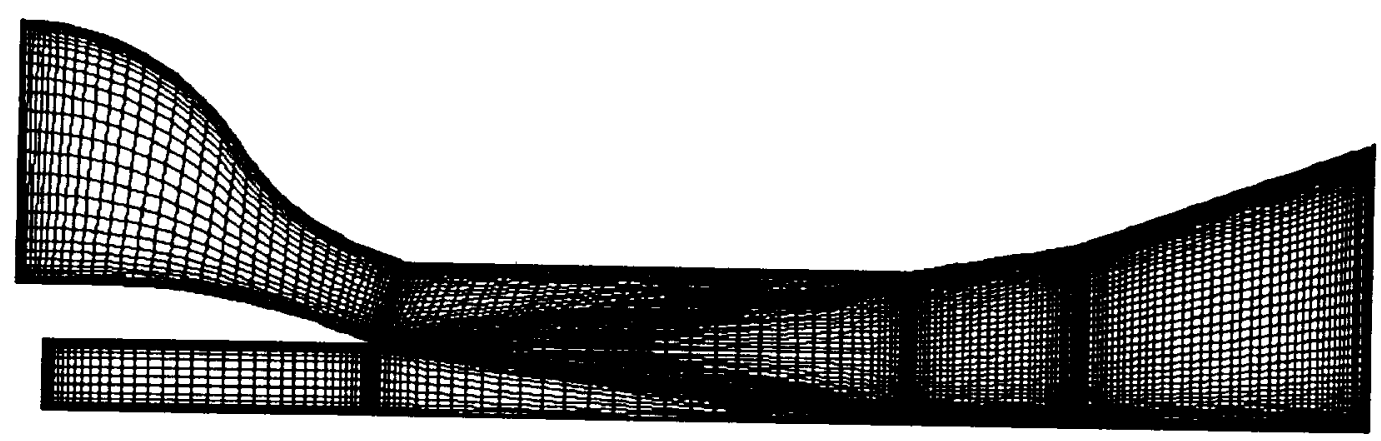

Fig. 3 Computational grid for baseline configuration

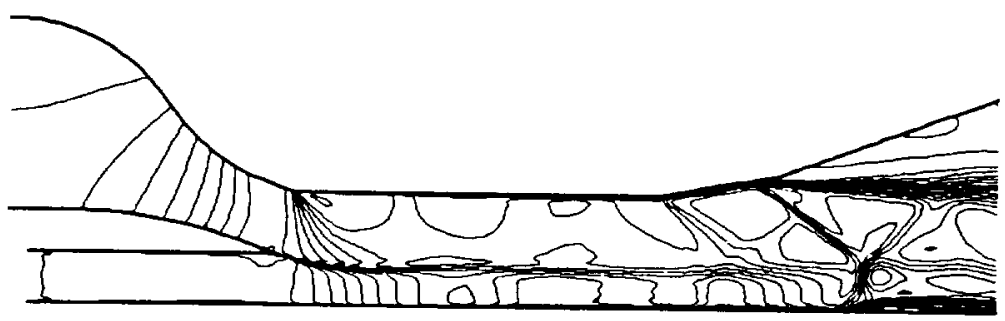

a) entire ejector

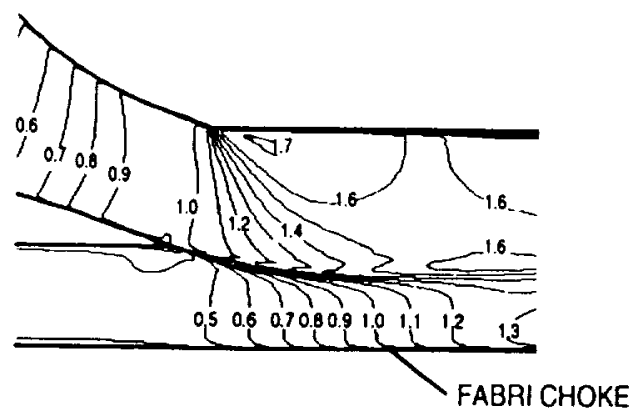

b) detail near entrance to mixing section

Fig. 4 Mach number contours for baseline configuration with $P_{7} / P_{\text {t.ram }}=0.508$

7

American Institute of Aeronautics and Astronautics 


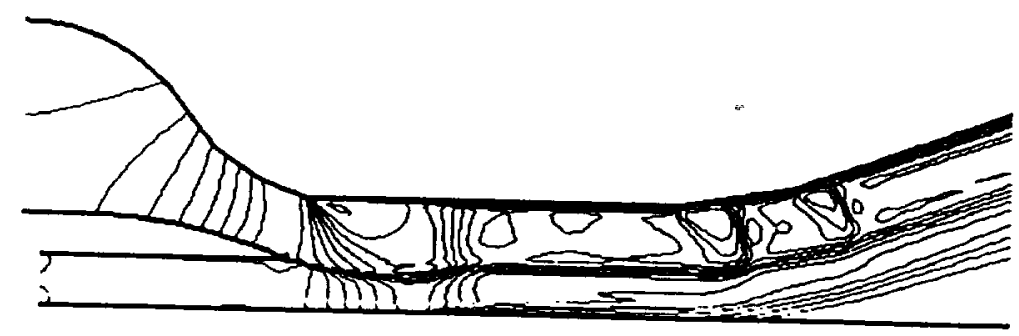

a) $\beta / \beta_{\max }=1.00, P_{6} / P_{1 . \text { ram }}=0.759$

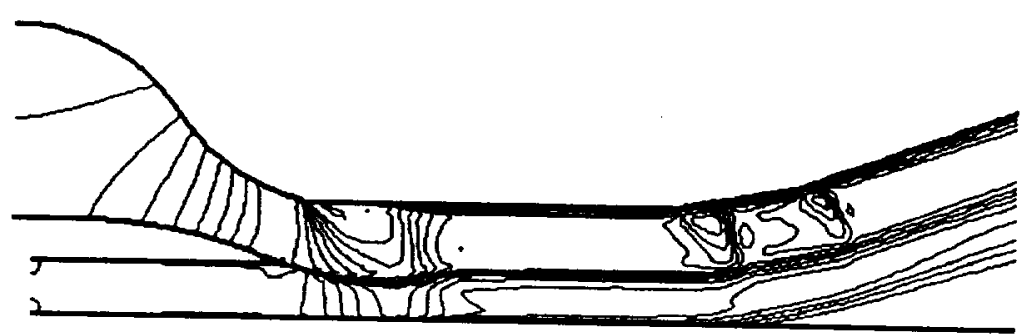

b) $\beta / \beta_{\max }=1.00, P_{6} / P_{t \cdot r a m}=0.775$

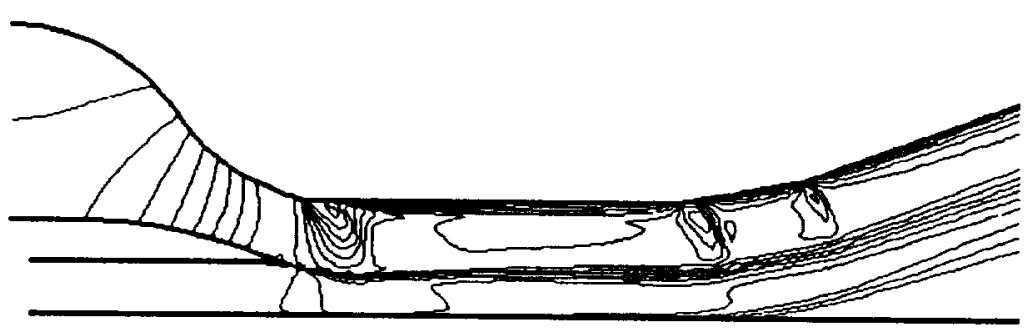

c) $\beta / \beta_{\max }=0.91, P_{6} / P_{1 . r 2 m}=0.811$

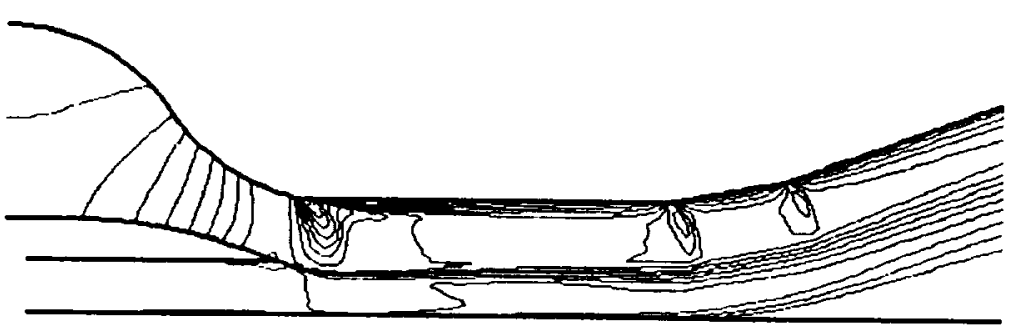

d) $\beta / \beta_{\max }=0.81, P_{6} / P_{t, r a m}=0.840$

Fig. 5 Mach number contours for baseline configuration near ejector-critical condition

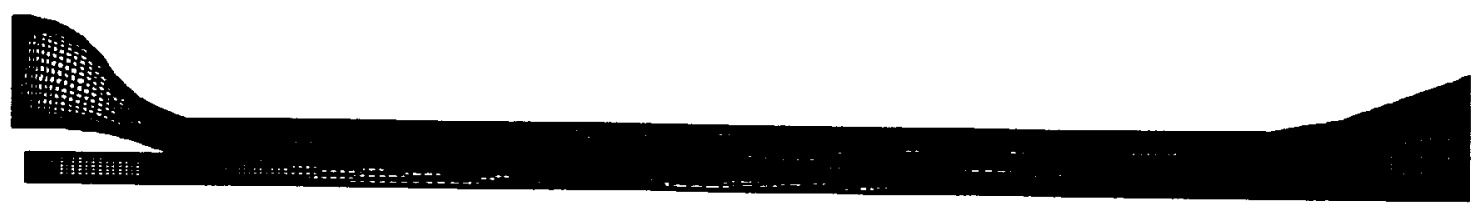

Fig. 6 Computational grid for long mixing section configuration 


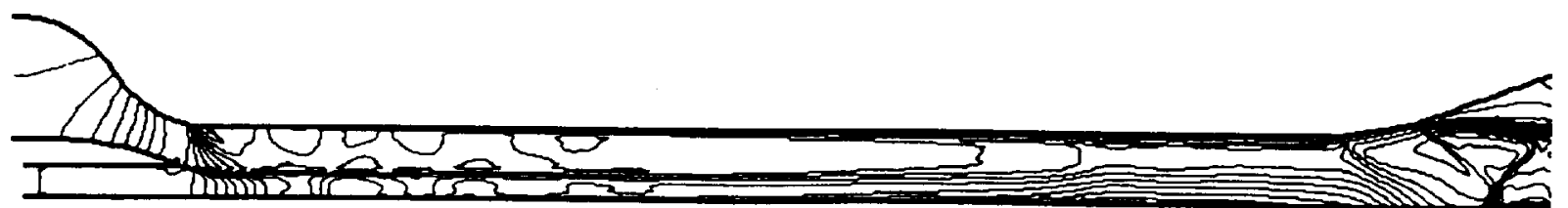

a) entire ejector

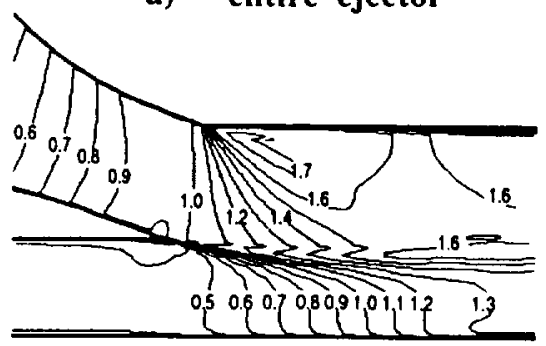

b) detail near entrance to mixing section

Fig. 7 Mach number contours for long mixing section configuration

(viscous ejector walls) with $P_{7} / P_{t \cdot r a m}=0.508$

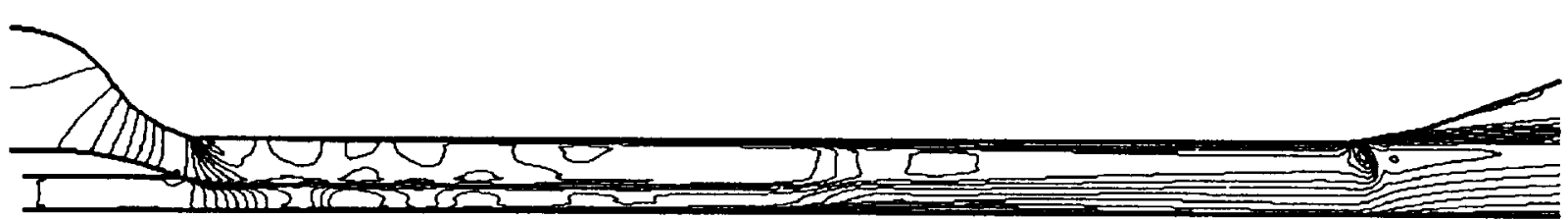

a) $\beta / \beta_{\max }=1.00, P_{6} / P_{1-\text { ram }}=0.702$

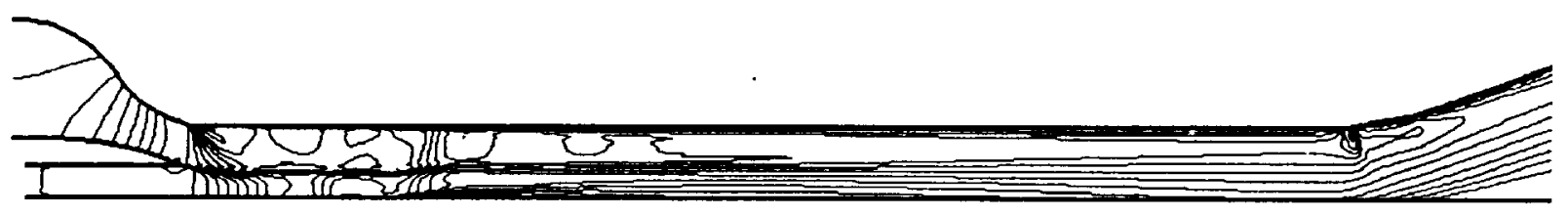

b) $\beta / \beta_{\max }=1.00, P_{6} / P_{1, \text { ram }}=0.761$

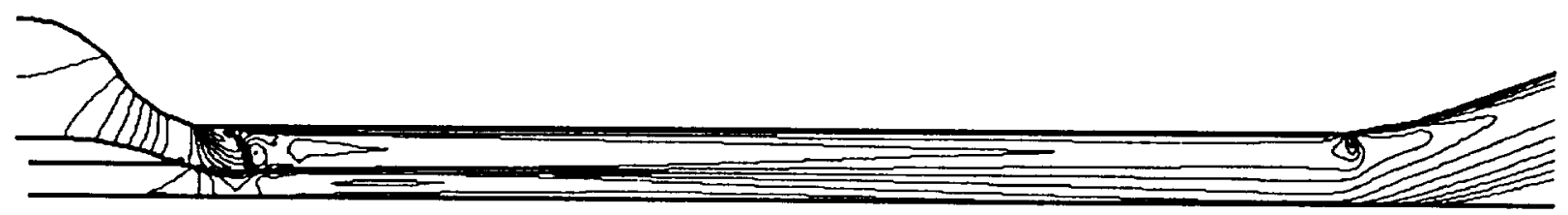

c) $\beta / \beta_{\max }=0.91, P_{6} / P_{\text {t.ram }}=0.789$

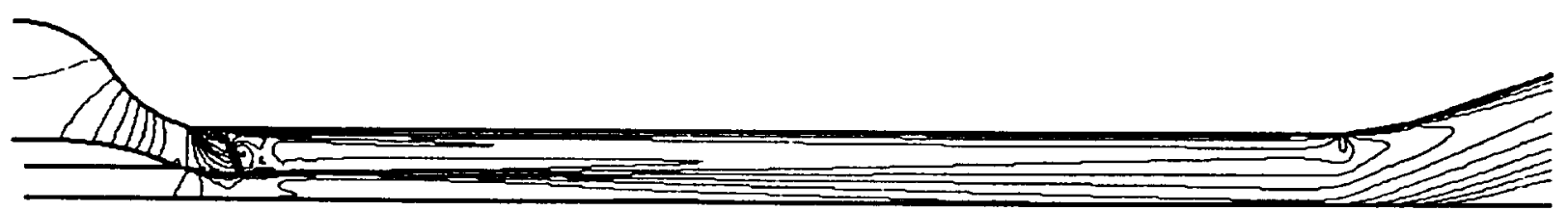

d) $\beta / \beta_{\max }=0.93, P_{6} / P_{\text {t.ram }}=0.837$

Fig. 8 Mach number contours for long mixing section configuration (viscous ejector walls) near ejector-critical condition 

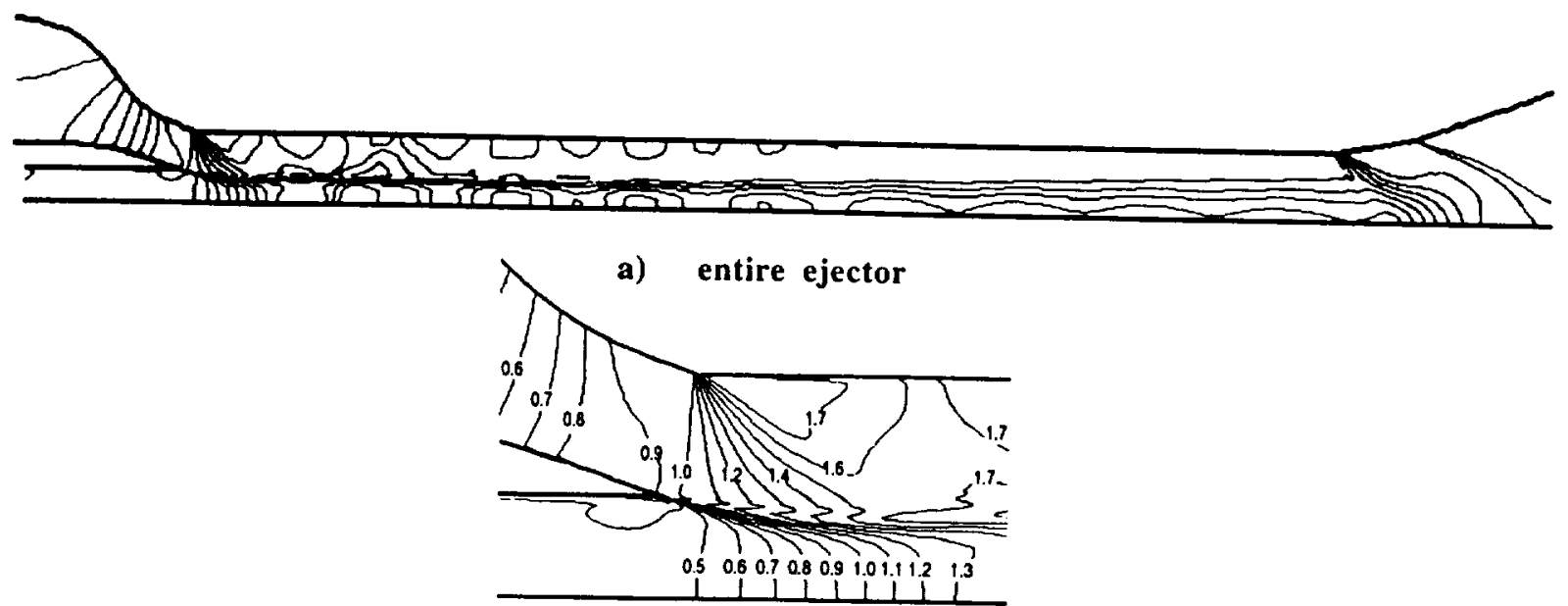

b) detail near entrance to mixing section

Fig. 9 Mach number contours for long mixing section configuration

(inviscid ejector walls) with $P_{7} / P_{t-r a m}=0.508$

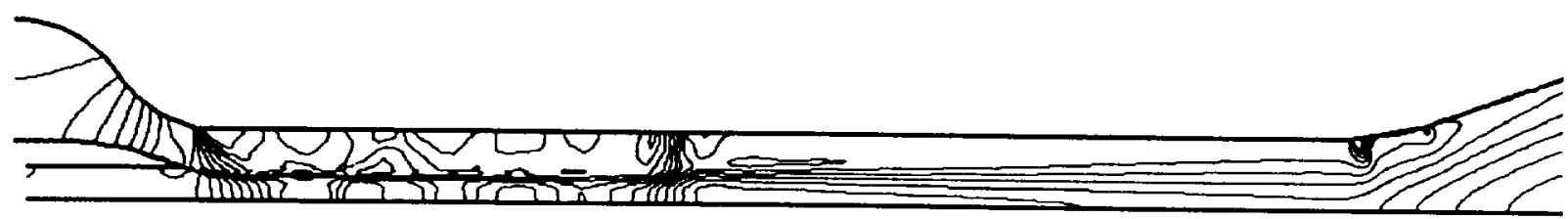

a) $\beta / \beta_{\max }=1.00, P_{6} / P_{t, \text { ram }}=0.866$

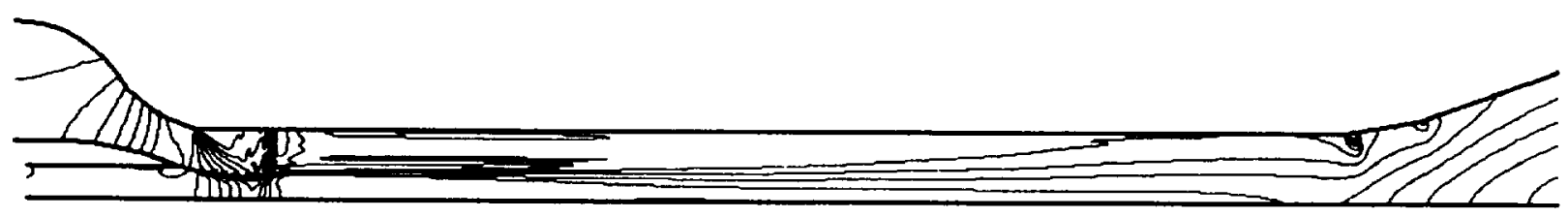

b) $\beta / \beta_{\max }=1.00, P_{6} / P_{\text {t.ram }}=0.887$

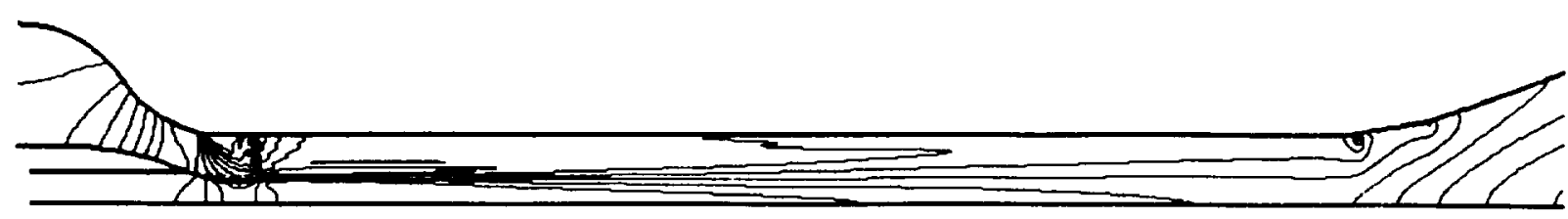

c) $\beta / \beta_{\max }=0.96, P_{6} / P_{1-r a m}=0.903$

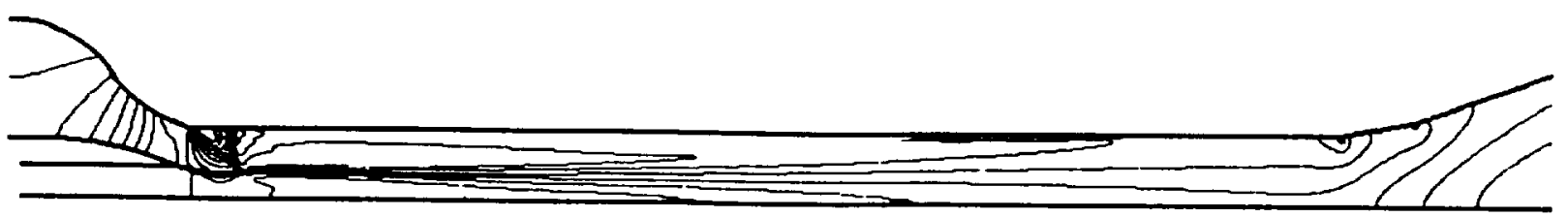

d) $\beta / \beta_{\max }=0.85, P_{6} / P_{t \cdot r a m}=0.972$

Fig. 10 Mach number contours for long mixing section configuration (inviscid ejector walls) near ejector-critical condition 


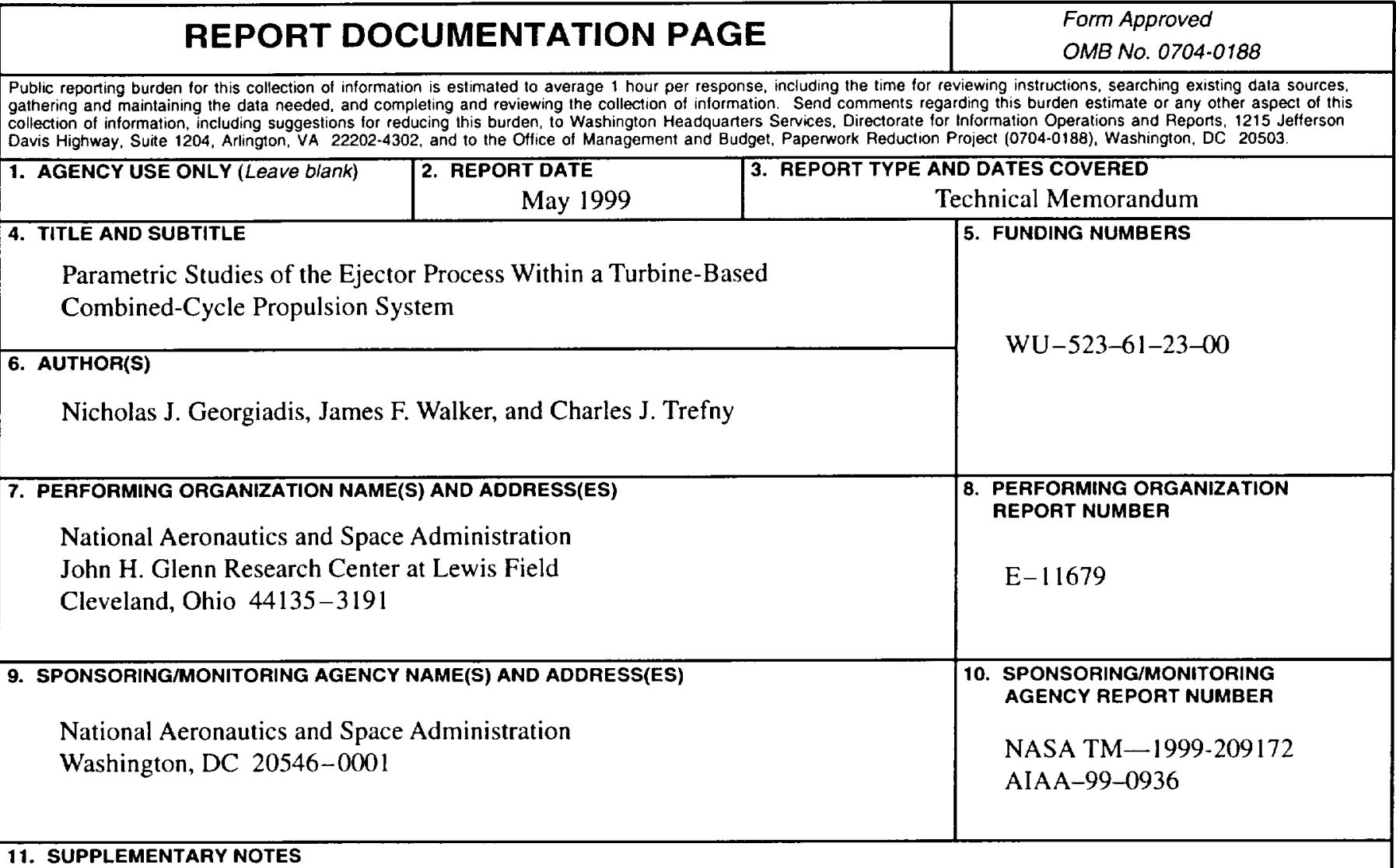

Prepared for the 36th Aerospace Sciences Meeting \& Exhibit sponsored by the American Institute of Aeronautics and Astronautics, Reno, Nevada, January 12-15, 1998. Responsible person, Nicholas J. Georgiadis, organization code 5860, (216) 433-3958.

12a. DISTRIBUTION/AVAILABILITY STATEMENT

Unclassified - Unlimited

Subject Categories: 02, 07, and 34 12b. DISTRIBUTION CODE

Distribution: Nonstandard

This publication is available from the NASA Center for AeroSpace Information, (301) 621-0390.

13. ABSTRACT (Maximum 200 words)

Performance characteristics of the ejector process within a turbine-based combined-cycle (TBCC) propulsion system are investigated using the NPARC Navier-Stokes code. The TBCC concept integrates a turbine engine with a ramjet into a single propulsion system that may efficiently operate from takeoff to high Mach number cruise. At the operating point considered, corresponding to a flight Mach number of 2.0, an ejector serves to mix flow from the ramjet duct with flow from the turbine engine. The combined flow then passes through a diffuser where it is mixed with hydrogen fuel and burned. Three sets of fully turbulent Navier-Stokes calculations are compared with predictions from a cycle code developed specifically for the TBCC propulsion system. A baseline ejector system is investigated first. The NavierStokes calculations indicate that the flow leaving the ejector is not completely mixed, which may adversely affect the overall system performance. Two additional sets of calculations are presented; one set that investigated a longer ejector region (to enhance mixing) and a second set which also utilized the longer ejector but replaced the no-slip surfaces of the ejector with slip (inviscid) walls in order to resolve discrepancies with the cycle code. The three sets of Navier-Stokes calculations and the TBCC cycle code predictions are compared to determine the validity of each of the modeling approaches.

\section{SUBJECT TERMS}

Turbine based combined cycle; Ejector nozzle; Turbulent mixing

17. SECURITY CLASSIFICATION OF REPORT

Unclassified

18. SECUAITY CLASSIFICATION
OF THIS PAGE
Unclassified

Unclassified
19. SECURITY CLASSIFICATION OF ABSTRACT Unclassified

NSN 7540-01-280-5500 


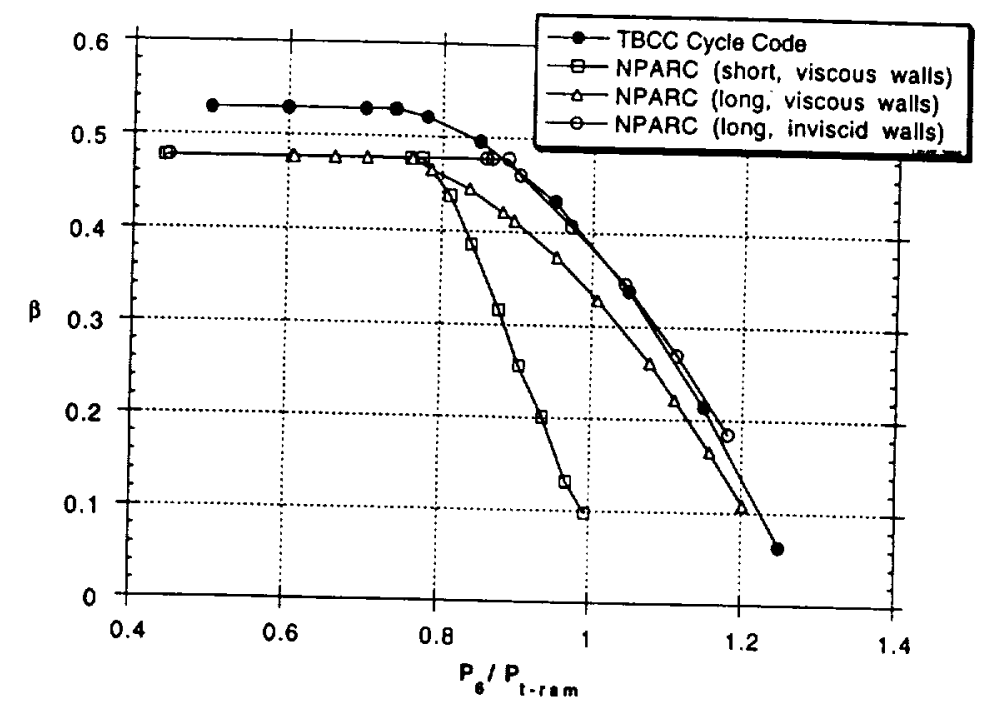

Fig. 11 Variation of entrained ramjet flow with pressure at end of mixing section

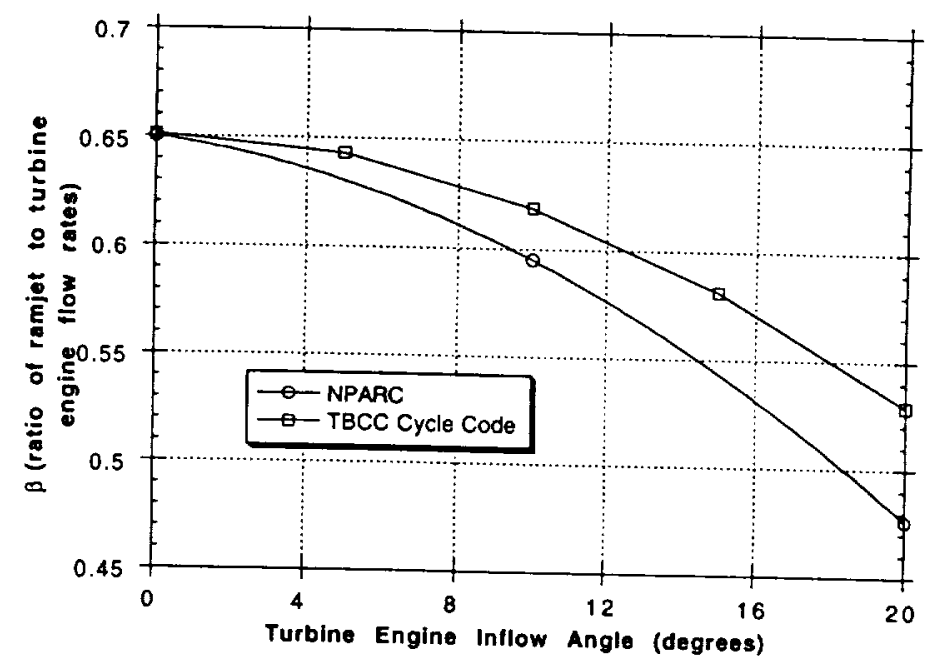

Fig. 12 Variation of maximum ramjet flow with confluence angle 